\title{
Study of gait using weighted vests on balance with paraplegic patients
}

\author{
Hyuk-Jae Choi ${ }^{1,2}$, Hyun-Joo Kang ${ }^{3, *}$ \\ 'Department of Physical Education, Graduate School, Soonchunhyang University, Asan, Korea \\ ${ }^{2}$ Korea Workers' Compensation \& Welfare Service, Rehabilitation Engineering Research Institute, Incheon, Korea \\ ${ }^{3}$ Department of Sports Medicine, College of Natural Sciences, Soonchunhyang University, Asan, Korea
}

The aims of this study were to identify static and dynamic balance with the addition of weighted vests for the rehabilitation of paraplegic patients. The study was conducted using weighted vest exercises with applied optimal weight ratios. Ten paraplegic patients who use custom orthosis were enrolled for experiments including static standing and dynamic gait with a weighted vest. We set weight ratios as $0 \%, 10 \%$, and $15 \%$ of the patients' weight. A plantar pressure device was used for static balance tests for excursion and velocity of center of pressure and we identified dynamic balance through the tool of Timed Up and Go (TUG) test. The results of static and dynamic balance in $0 \%, 10 \%$, and $15 \%$ weight ratios did not have statistically significant differences, but we found an increasing tendency of sway excursion from nonweight
$(0 \%)$ to weight ratios $(10 \%, 15 \%)$ in static balance when weight is applied. Sway excursion in anteroposterior direction is greater than mediolateral sway. In dynamic balance, the TUG results showed a more delayed time when weight ratios were applied. In conclusion, we have to focus on balance training with anteroposterior direction to upgrade a patient's balance and prevent falls. Exercises with weighed vests are more useful than nonweighted but there is no difference between $10 \%$ and $15 \%$ weight ratios. Weighted vest exercises may play a role in the rehabilitation of balance in those with paraplegia.

Keywords: Weighted vest, Gait, Balance, Paraplegic patients, Timed Up and Go test

\section{INTRODUCTION}

The damage of the central nerve system due to traffic accidents, industrial disasters, and disease which cause a permanent syndromes such as paralysis and make the physical activity very difficult due to the problems of the sensory and motor nerve (Braddom et al., 2007). Paraplegic patients (PP) who can do physical activities by using upper limbs can walk by using various gait-assistant-aids and these aids account for an important part in the patient's rehabilitation (Hussey and Stauffer, 1973). Gait exercise can prevent various complications that can appear after the damage (DeLisa et al., 2005).

Therefore, PP are constantly participating in gait activities by means of the proper aid to perform gait. Starting from the standing-up workout and maintaining the static and dynamic balance by wearing the orthosis is important for the patient's stability and coordination.

For this reason, the study for improving the stability in various ways for PP was reported (Richardson et al., 2001). Although it was reported that proper load stimulus with proportionally weight changed the muscle activities and was effective for improving the balance ability following various reflective mechanisms and sways (Bastiaanse et al., 2000), the study pursuing stability by using the weighted vest (WV) is insufficient. Although the load stimulus using the WV is effective for muscle and balance enhancement, these results were confined to the normal persons and the stroke patients, and there are few studies which applied it to the PP. The ultimate purpose of the rehabilitation for PP is to enhance the static and dynamic balance and reduce the postural sway velocity in the up-right position. Therefore, the
${ }^{*}$ Corresponding author: Hyun-Joo Kang (D) http://orcid.org/0000-0001-9810-4040 Department of Sports Medicine, College of Natural Sciences, Soonchunhyang University, 22 Soonchunhyang-ro Sinchang-myeon, Asan 31538, Korea Tel: +82-41-530-1280, Fax: +82-41-530-1297, E-mail: violethjk@hanmail.net Received: May 11, 2017 / Accepted: June 5, 2017
This is an Open Access article distributed under the terms of the Creative Commons Attribution Non-Commercial License (http://creativecommons.org/licenses/by-nc/4.0/) which permits unrestricted non-commercial use, distribution, and reproduction in any medium, provided the original work is properly cited. 
purpose of this study was to suggest basic data by surveying the difference in balance following the addition of a load stimulus by means of the WV, targeting those with spinal cord injury. Results of this study can be used to develop an effective and systematic load stimulus exercise program for the future.

\section{MATERIALS AND METHODS}

\section{Participants}

The study was conducted targeting PP $(\mathrm{n}=10)$ on the thoracic and lumbar vertebra injury. The study was conducted through voluntary participation after obtaining consent and after explaining the experiment fully before the study progressed. It had been more than 2 years since all subjects were injured. The subjects who were comparatively healthy and did not undergo a sudden health change were selected except for ones with paralysis disability. The information on the 10 subjects who participated in this study is recorded in Table 1.

\section{Evaluation equipment and tools Plantar pressure system}

Plantar pressure measuring system (Pedar-X-32, Novel GmbH, München, Germany) was used to analyze the displacement value on the sensor in the form of an insole as long as $260-280 \mathrm{~mm}$. We measured the center of pressure $(\mathrm{CoP})$ to observe the migration excursion and the time on the anteroposterior (AP) and mediolateral (ML) displacement (Fig. 1). As for the sampling rate, the $\mathrm{CoP}$ which appeared in the insole sensor was analyzed according to the excursion of $\mathrm{CoP}$ at a rate of 50 times per second.

Table 1. Physical characteristics of the spinal cord injury subjects $(n=10)$

\begin{tabular}{lc}
\hline Characteristic & Value \\
\hline Gender & \\
Men & 9 \\
Women & 1 \\
Age $(\mathrm{yr})$ & $52.40 \pm 6.20$ \\
Height $(\mathrm{cm})$ & $167.90 \pm 4.38$ \\
Weight $(\mathrm{kg})$ & $66.80 \pm 5.90$ \\
Injury lever & \\
Thoracic spinal cord injury & 7 \\
Lumbar spinal cord injury & 3 \\
America Spinal Injury Association & \\
Complete injury & 7 \\
Incomplete injury & 3 \\
Onset year & $2,007.30 \pm 4.40$
\end{tabular}

Values are presented as mean \pm standard deviation.

\section{Static and dynamic balance test}

The static balance was measured by measuring the migration excursion and the velocity on the AP and ML directions of $\mathrm{CoP}$ in the static upright position for $10 \mathrm{sec}$. The evaluation on the dynamic balance was conducted by using the Timed Up and Go (TUG) test for overall evaluation of functional movement and movement ability (Griffin et al., 2003). If the tester gives the subject the start sign, the subject stands up from the chair and returns from the cone spot, $3 \mathrm{~m}$ away (Ng and Hui-Chan, 2005).

\section{Weighted vest}

The WV of Healthway (Korea) which fits a steel block in the front and back side was selected for the load stimulus. The WV shown in Fig. 2 was designed to have each pocket carry a block and allows for easy control of the loads following the weight for each subject.

\section{Experimental procedure}

A balance evaluation was conducted for all subjects before applying the WV, while the decision on the load weight was con-

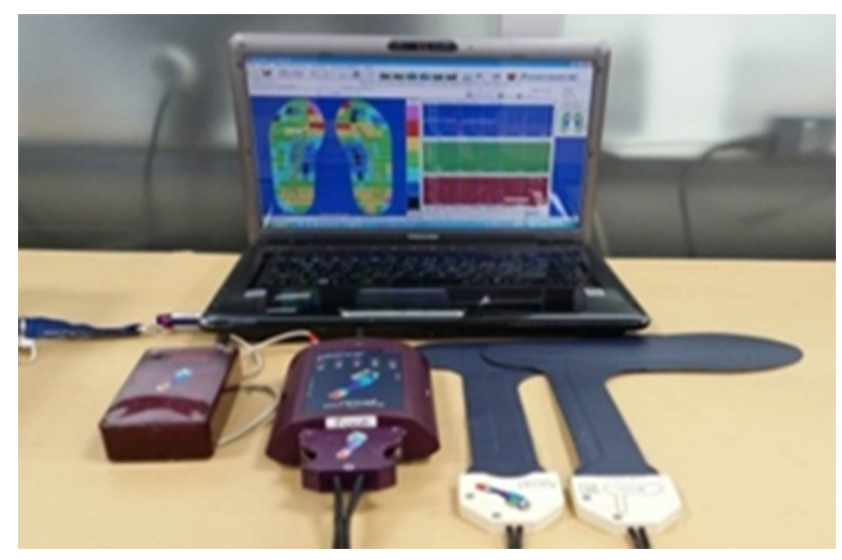

Fig. 1. Plantar pressure system (Pedar-X-32, Novel GmbH, München, Germany).
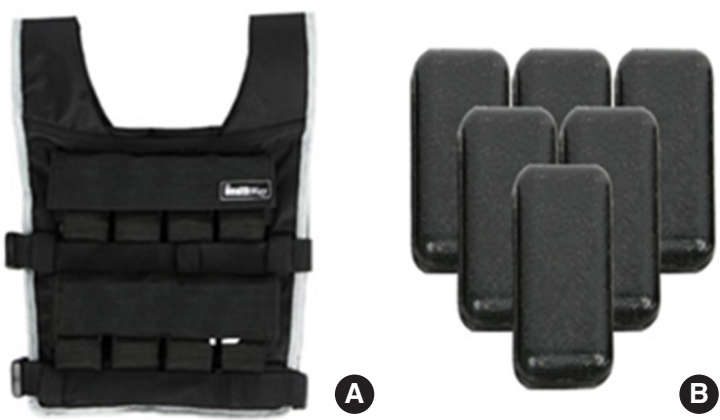

Fig. 2. Weighted vest (A) and steel bar (B). 
ducted based on a previous study (Griffin et al., 2003). We had three randomly selected stages of load variables for the gait evaluation: no-load (0\%), and a load for $10 \%$ and $15 \%$. The static and dynamic balance tests were conducted targeting all subjects with hip-knee-ankle-foot-orthosis including support and protection function, from the torso to plantar parts for safety.

The dynamic balance evaluation was conducted on the fixed parallel bars, as well as on a wide, low wooden table that gave a sense of stability during TUG test. The self-selected velocity that they walked most safely and conveniently was measured with the TUG test. Fig. 3 is the figure used when conducting the load gait and the balance test. The easy experiment was conducted more than three times in order to familiarize the subjects.

\section{Statistical analyses}

IBM SPSS ver. 18.0 (IBM Co., Armonk, NY, USA) was used for the statistical analysis on the results of this study showing the mean and the standard deviation.

Nonparametric method analysis (Kruskal-Wallis $H$ Test) was conducted through regularity testing examination of the entire
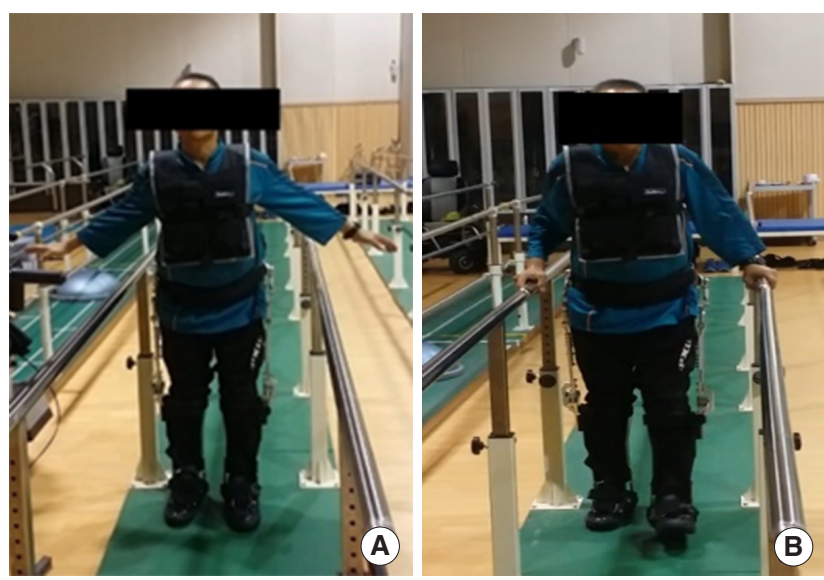

Fig. 3. Static (A) and dynamic (B) balance test. results in order to figure out the difference among the sway velocity of the AP and ML direction, and balance following the load weight $(0 \%, 10 \%$, and $15 \%)$ with 10 subjects. The difference was examined by means of the Bonferroni method for the post hoc. The statistical significance level $(\alpha)$ was set as 0.05 .

\section{RESULTS}

\section{Static balance}

The static balance results were shown by classifying the sway velocity and excursion of the AP and ML direction (Table 2).

\section{AP sway velocity and excursion}

The average sway velocity on the AP directions of 10 subjects was $2.64 \pm 0.66 \mathrm{~cm} / \mathrm{sec}$ in the $0 \%$ nonload, $2.68 \pm 1.23 \mathrm{~cm} / \mathrm{sec}$ in the $10 \%$ load, and $2.44 \pm 0.92 \mathrm{~cm} / \mathrm{sec}$ in the $15 \%$ load. There was no significant difference between the average and the standard deviation on the sway velocity of the AP directions, and there were no results which showed the statistically significant difference in each load stage $(P=0.828)$. The average sway excursion was shown as $0.70 \pm 0.55 \mathrm{~cm}$ in the nonload of $0 \%, 1.25 \pm 1.02 \mathrm{~cm}$ in $10 \%$ load, and $1.96 \pm 1.85 \mathrm{~cm}$ in $15 \%$ load.

Although the average on the sway excursion tended to increase in the load condition compared to the non-load of $0 \%$, the result of a statistically significant level were not shown $P=0.102$.

\section{$M L$ sway velocity and excursion}

The average sway velocity on the ML directions were shown as $0.73 \pm 0.20 \mathrm{~cm} / \mathrm{sec}, 0.73 \pm 0.30 \mathrm{~cm} / \mathrm{sec}$, and $0.68 \pm 0.27 \mathrm{~cm} / \mathrm{sec}$ each in $0 \%, 10 \%$, and $15 \%$ loads. Although it was remarkably lower than the sway velocity of the AP directions, there were not statistically significant differences like the results of the AP direction sway velocity $(P=0.877)$. The sway excursion on the ML directions was shown as $0.17 \pm 0.12 \mathrm{~cm}$ in the $0 \%$ nonload, $0.28 \pm$

Table 2. Results of static balance according to weight ratio

\begin{tabular}{|c|c|c|c|c|}
\hline \multirow{2}{*}{ Variable } & \multicolumn{3}{|c|}{ Weight-ratio (\%) } & \multirow{2}{*}{$P$-value } \\
\hline & 0 & 10 & 15 & \\
\hline \multicolumn{5}{|c|}{ Anteroposterior sway } \\
\hline Velocity (cm/sec) & $2.64 \pm 0.66$ & $2.68 \pm 1.23$ & $2.44 \pm 0.92$ & 0.828 \\
\hline Excursion $(\mathrm{cm})$ & $0.70 \pm 0.55$ & $1.25 \pm 1.02$ & $1.96 \pm 1.85$ & 0.102 \\
\hline \multicolumn{5}{|l|}{ Mediolateral sway } \\
\hline Velocity (cm/sec) & $0.73 \pm 0.20$ & $0.73 \pm 0.30$ & $0.68 \pm 0.27$ & 0.877 \\
\hline Excursion $(\mathrm{cm})$ & $0.17 \pm 0.12$ & $0.28 \pm 0.22$ & $0.33 \pm 0.27$ & 0.263 \\
\hline
\end{tabular}

Values are presented as mean \pm standard deviation. 
Table 3. Results of dynamic balance according to weight ratio

\begin{tabular}{lcccc}
\hline & & Weight-ratio $(\%)$ & 15 & $P$-value \\
\cline { 2 - 5 } & 0 & 10 & $23.33 \pm 3.64$ & 0.085 \\
\hline Timed Up and Go test & $19.53 \pm 4.47$ & $23.42 \pm 4.63$ & \\
\hline
\end{tabular}

Values are presented as mean \pm standard deviation.

$0.22 \mathrm{~cm}$ in the $10 \%$ load, and $0.33 \pm 0.27 \mathrm{~cm}$ in the $15 \%$ load. Although the result on the average and the standard deviation tended to increase as the load increased, a statistically significant difference was not shown $(P=0.263)$.

\section{Dynamic balance}

The change to the dynamic balance with the load conditions of $0 \%, 10 \%$, and $15 \%$ each are shown in Table 3 . The dynamic balance results during the change from the no-load to the $10 \%$ load tended to increase by an average $3.89 \pm 5.40 \mathrm{sec}$ and the subject's results increased by a maximum $16.40 \mathrm{sec}$. When the load was changed from $0 \%$ to $15 \%$, the average tended to increase by $3.80 \pm 3.50 \mathrm{sec}$ including the subjects where the results increased by a maximum of $8.80 \mathrm{sec}$. Significant difference was not shown when it the weight was increased from $10 \%$ to $15 \%$. The TUG total average result of the subjects were shown as $19.53 \pm 4.47 \mathrm{sec}$, $23.42 \pm 4.63 \mathrm{sec}$, and $23.33 \pm 3.64$ sec each in $0 \%, 10 \%$, and $15 \%$, and statistically significant difference was not shown $(P=0.085)$.

\section{DISCUSSION}

In the load ratio $(0 \%, 10 \%$, and $15 \%)$ was set according to patient's weight and the static and dynamic balance test conducted. The pilot-test was conducted targeting PP based on the case of applying 10\% (Griffin et al., 2003) in proportion to the subjects' weight while the previous study applied $7 \%$ (Shin et al., 2011) to the stroke patients. It was presumed the $10 \%$ and $15 \%$ loads were appropriate in the pilot-test process with an increased from $1 \%$ to $7 \%$ load.

As for exceeding the $15 \%$ load, Subjects complained of the burden, making the tests difficult to conduct. Although the experiment should be conducted by applying the degree of support differently depending on the damage level and the degree of the spinal cord injury, it was conducted in the safest conditions for the subjects' safety. This study decided on the $10 \%$ and $15 \%$ load weights which were different from the lower weight ratios used in a previous study. While normal persons or cerebral palsy patients could stand up or walk independently, adapting to the load of the heavy ratio, PP could not perform the most basic motions without orthosis and received many restrictions. Therefore, the experiment was conducted by setting the weight applied to the $\mathrm{WV}$ at the low level and paying attention to the subjects and safety to avoid accident.

Although the previous study analyzed the energy metabolism on the active mass of the lower limb muscle and muscular strength with a load, the muscles on the voluntary lower limbs of the PP did not contract, and the muscles decreased and shrined. Our study was conducted to determine a more in-depth analysis on the sway and balance of the $\mathrm{CoP}$ by means of the plantar pressure measuring equipment rather than an evaluation on the muscles.

As for the sway velocity and excursion of the AP and ML directions, a significant difference was not shown in regards to the static and dynamic balance results with the load but the tendency was shown. In conclusion, the emphasis should be placed on balance improvement noting injuries from a fall in AP directions because the sway excursion and velocity are higher in AP directions than in ML directions based on the tendency on the results of the static balance test.

Although there was no significant difference statistically in the dynamic balance result, when loads of $10 \%$ and $15 \%$ were applied to the exercise method following the PPs' load, the dynamic balance change was not affected and stability was maintained. Through this study, it is expected that WV exercise should be a foundation for exercise mediation methods, as the maintenance and improvement of balance ability is the ultimate purpose of rehabilitation.

\section{CONFLICT OF INTEREST}

No potential conflict of interest relevant to this article was reported.

\section{ACKNOWLEDGMENTS}

This work was supported by the Soonchunhyang University Research Fund (No. 20170601). 


\section{REFERENCES}

Bastiaanse CM, Duysens J, Dietz V. Modulation of cutaneous reflexes by load receptor input during human walking. Exp Brain Res 2000;135: 189-198.

Braddom RL, Chan L, Harrast MA, Kowalske KJ, Matthews DJ, Ragnarsson KT, Stolp KA, editors. Physical medicine \& rehabilitation. 3rd ed. Philadelphia (PA): Elsevier; 2007.

DeLisa JA, Gans BM, Walsh NE, Bockenek WL, Pease WS, Frontera WR, Robinson LR, Geiringer SR, Smith J, Gerber LH, Stitik TP, Zafonte RD, editors. Physical medicine and rehabilitation: principles and practice. 4th ed. Philadelphia (PA): Lippincott Williams \& Wilkins; 2005.

Griffin TM, Roberts TJ, Kram R. Metabolic cost of generating muscular force in human walking: insights from load-carrying and speed experiments. J Appl Physiol (1985) 2003;95:172-183.

Hussey RW, Stauffer ES. Spinal cord injury: requirements for ambulation. Arch Phys Med Rehabil 1973;54:544-547.

$\mathrm{Ng}$ SS, Hui-Chan CW. The timed up \& go test: its reliability and association with lower-limb impairments and locomotor capacities in people with chronic stroke. Arch Phys Med Rehabil 2005;86:1641-1647.

Richardson JK, Sandman D, Vela S. A focused exercise regimen improves clinical measures of balance in patients with peripheral neuropathy. Arch Phys Med Rehabil 2001;82:205-209.

Shin SH, Lee KJ, Song CH. The effect of weight based gait training using weighted vest on static balance and dynamic balance with stroke. J Spec Educ Rehabil Sci 2011;50:413-431. 